\section{Affiliation in rats under stress *}

\author{
BIBB LATANÉ \\ Ohio State University, Columbus, Ohio 43210 \\ and \\ LUCY FRIEDMAN and JAMES THOMAS \\ Columbia University, New York, N.Y. 10027
}

Rats tested in a two-compartment shuttlebox with another rat tethered in one compartment showed strong preference for the compartment with the other rat. Rats given the same test with the addition of intermittent shocks showed no preference for the other rat. This result indicates that fear does not necessarily lead to affiliation in rats and that pain-produced aggression (shocked rats often fought) is not necessarily reinforcing.

Rats, like many other animals, show fewer signs of fear when they are together than when they are alone. They defecate less, and they are less likely to freeze when in the presence of other rats (Davitz \& Mason, 1955; Latané, 1969; Latané \& Glass, 1968; Morrison \& Hill, 1967). It is possible that one reason why rats affiliate is that, by doing so, they can reduce fear. If so, we should expect rats to be more affiliative when they are tested in a fear-increasing environment than when they are tested in a nonfearful environment.

Rats, like many other animals, often fight when they are exposed to noxious stimulation such as electric shock (Ulrich \& Azrin, 1962). If fighting satisfies pain-induced aggressive needs, we might expect rats to seek out other rats when tested in an environment in which they receive noxious stimulation. Indeed, Dreyer \& Church (1970) have shown that when faced with inescapable electric shock, rats chose that arm of a T-maze containing another rat in preference to an empty arm. Unfortunately, Dreyer and Church did not include a control group in which rats could choose to affiliate when not faced with electric shock.

Recent studies (Latané, 1969; Latané \& Glass, 1968) have shown that rats are extremely sociable animals when tested under normal circumstances. It is the purpose of the present study to see whether social attraction will be increased when rats are tested under conditions where they receive fright-inducing fight-producing inescapable shocks.

SUBJECTS AND APPARATUS

Sixteen experimentally naive male albino rats (Cernac Farms) were 30 days old at the start of the testing. They were housed individually in wire

*This research was partially supported by NSF Grants GS 1239 and GS 2292 and by the Columbia University Council for Research in the Social Sciences. Request reprints from Bibb Latané, $404 \mathrm{C}$ West $17 \mathrm{th}$ Avenue, Columbus, Ohio 43210 . mesh cages on an ad lib food and water schedule and tested in a metal shuttlebox, divided into two compartments with a $3 \times 5$ in. connecting doorway. Each compartment was $11 \frac{1 / 2}{2} 10 \times 15$ in. high and was floored with 3/16-in. stainless steel bars set $3 / 4$ in. apart. One compartment was painted flat black and the other flat white; otherwise, they did not differ. Shock was delivered through a Grason-Stadler generator and scrambler.

\section{PROCEDURE}

Each rat was tested in the shuttlebox for $5 \mathrm{~min}$ a day for 20 days. On alternate days, a "stimulus" rat of the same age and background was loosely tethered in the compartment opposite to the one in which the rat was placed. Tethered rats had enough freedom of movement to rear up and to move about through the rear half of their compartment; they could not cross into the opposite compartment.

On alternate, "baseline" days, Ss were tested alone in the shuttlebox. In addition to this alternation between "alone" and "together" testing conditions, rats were alternately placed in either the white or black side of the shuttlebox.

Half the rats were assigned condition for the first 12 days of testing; half were tested under shock for the entire 20 days of the experiment. In the latter condition, unavoidable 1-mA shocks were delivered to both compartments on a random schedule at the rate of $2 / \mathrm{min}$ throughout the test period. On the "together" days, both the $S$ and the tethered stimulus rat received shock. On the 13 th day of testing, rats in the "no-shock" condition began receiving shock and continued to do so throughout the remainder of the experiment.

\section{RESULTS}

Affiliation in the

\section{No-Shock Condition}

When alone in the shuttlebox, rats spent $60.4 \%$ of their time in the randomly to a "no-shock" testing compartment into which they were initially placed and only $39.6 \%$ of their time in the opposite compartment. This preference for the side of initial placement was of equal magnitude in the shock and no-shock conditions and remained constant throughout the experiment. Since the tethered rat in the "together" conditions was always located in the side opposite initial placement, we would expect that, if rats had no attraction to or repulsion from the other rat, they would spend about $40 \%$ of the test period in the compartment with him. Instead, they spent $77 \%$ of their time with the tethered rat $(p<.001)$, which is significantly higher even than a 50-50 division of time. ${ }^{1}$ This result confirms, in a new test situation, the findings by Latané (1969) and Latané \& Glass (1968) that rats are highly gregarious when allowed to make physical contact and interact with each other.

As in previous studies, rats tended to defecate less when together than alone in the no-shock condition. When alone, the average rat dropped 1.83 boluses per day; when with a tethered rat, only 1.17 were dropped $(p<.10)$. Shock substantially increased defecation in both conditions to an average of 8.25 boluses per day $(\mathrm{p}<.001)$.

Effects of Shock on Affiliation

Far from increasing affiliation, shock led to a significant decrease in the amount of time spent with the tethered rat. Over the entire course of the experiment, rats in the shock condition spent $37.2 \%$ of their time in the compartment with the tethered rat, not significantly different from the $40 \%$ baseline rate but much lower than the $77 \%$ exhibited by nonshocked rats $(p<.01)$. Each of the eight no-shock rats became less

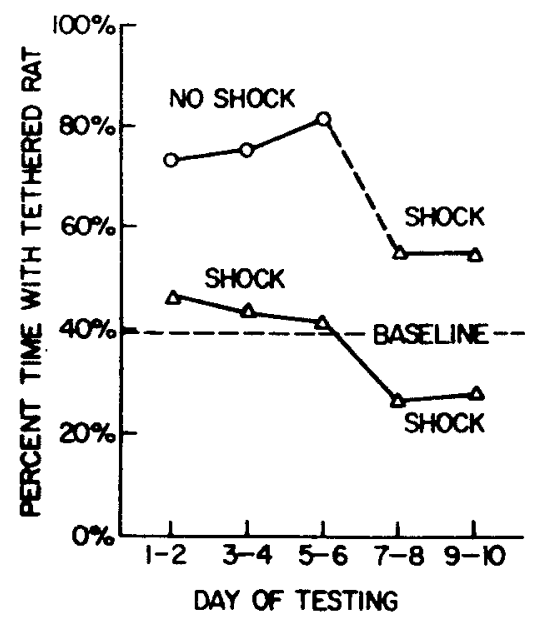

Fig. 1. Effects of shock on gregariousness in rats $(N=8$ per data point). 
sociable when shock was introduced $(p<.01)$. Figure 1 presents these results.

Shocked rats showed no signs of significant attraction to the tethered rat, and with experience, they even learned to avoid it. Rats in the shock condition spent less time with the tethered rat at the end of the experiment than at the beginning $(\mathrm{p}<.02)$, and by the last four test periods, each of the eight rats in this condition spent less time with the tethered rats $(27 \%)$ than in the comparable empty compartment $(\mathrm{p}<.05)$.

\section{DISCUSSION}

Humans are more likely to affiliate when under stress (Schachter, 1959), and shared stress can lead them to increased liking (Latané, Eckman, \& Joy, 1966). In the present experiment, rats seem to show the opposite reactions. Although nonshocked rats showed fewer signs of fear when together than when alone, shock stress led to decreased rather than increased attraction.

One reason for this might be that shock so disrupted the rats that they could no longer discriminate or choose between empty compartments and compartments containing a tethered rat. Rats' color preferences provide evidence consistent with this view of the effect of shock. In the alone, nonshock condition, rats showed a consistent preference for the black compartment $(57 \%)$ over the white compartment $(43 \%, \mathrm{p}<.05)$. Under shock, this preference largely disappeared $(51 \%-49 \%$, n.s.). This view, however, does not explain the fact that shocked rats became less gregarious with experience and that shocked rats showed a significant repulsion from the tethered stimulus rat by the end of the experiment.

Although the presentation of shock was not contingent on which compartment the $S$ was in, it is possible that Ss learned to associate the tethered rat with shock. This could have resulted from some "superstition" caused by accidental pairing of shock with approach to the other or from the potency of the cue of the other rat, which was probably much stronger than that of any other feature of the shuttlebox. It is also possible that the shock directly influenced the nature of the interaction between animals, making it less pleasant.

Rats in the shock condition did spend a considerable proportion of their time with the tethered rat fighting. Other investigators have suggested that the opportunity to aggress can be positively reinforcing. The present results, however, suggest that pain-produced fighting is not necessarily reinforcing to the rat and in fact may be more aversive than mere pain. In this respect, rats appear to differ from squirrel monkeys, who will learn to pull a chain for the opportunity to aggress when shocked (Azrin, Hutchinson, \& McLaughlin, 1965).

\section{REFERENCES}

AZRIN, N, H. HUTCHINSON, R. R., \& McLAUGHLIN, R. The opportunity for aggression as an operant reinforcer during aversive stimulation. Journal of the Experimental Analysis of Behavior, 1965, 8, 171-180.

DAVITZ, J. R., \& MASON, D. J. Socially facilitated reduction of a fear response in rats. Journal of Comparative \& Physiological Psychology, 1955, 48, 149-151.

DREYER, P. I., \& CHURCH, R. M. Reinforcement of shock-induced fighting. Psychonomic Science, 1970, 18, 147-148.

LATANE, B. Gregariousness and fear in laboratory rats. Journal of Experimental Social Psychology, 1969, 5, 61-69.

LATANÉ, B., ECKMAN, J., \& JOY, V. Shared stress and interpersonal attraction. Journal of Experimental Social Psychology, 1966, Supplement 1, 80-94.

LATANE, B., \& GLASS, D. C. Social and nonsocial attraction in rats. Journal of Personality \& Social Psychology, 1968, 9. 142-146.

MORRISON, B. J., \& HILL, W. F. Socially facilitated reduction of the fear response in rats raised in groups or in isolation. Journal of Comparative \& Physiological Psychology, 1967, 63, 71-76.

SCHACHTER, S. The psychology of affiliation. Stanford: Stanford University Press, 1959

ULRICH, R. E., \& AZRIN, N. H. Reflexive fighting in response to aversive stimulation. Journal of the Experimental Analysis of Behavior, 1962, 5, 511-520. NOTE

1. All $p$ values are based on two-tailed $t$ tests or sign tests. 